\title{
The Role of Teleological Thinking in Learning the Darwinian Model of Evolution
}

\author{
Leonardo Martín González Galli • Elsa N. Meinardi
}

Published online: 19 October 2010

(C) Springer Science+Business Media, LLC 2010

\begin{abstract}
Human beings are predisposed to think of evolution as teleological-i.e., having a purpose or directive principle - and the ways scientists talk about natural selection can feed this predisposition. This work examines the suggestion that students' teleological thinking operates as an obstacle when the natural selection evolution model is taught. What we mean by obstacle is an established way of thinking that resists change due to its explanatory power. In light of this approach, the challenges of teaching evolution in biology education have been revised, and improved methodological strategies aimed at a better comprehension of the Darwinian evolution model are suggested.
\end{abstract}

Keywords Evolutionary theory - Natural selection . Teleology $\cdot$ Misconceptions $\cdot$ Obstacle $\cdot$ Teaching process . Learning process

\section{Introduction}

The goal of evolutionary biology is to trace the evolution of organisms as well as to understand the mechanisms that trigger evolutionary change. Therefore, evolutionary biology ultimately analyzes the reasons why a biological system has evolved in a particular manner-what Ernst Mayr (1997) has called the "ultimate causes" of a biological phenomenon. The implications of evolution theory far

\footnotetext{
L. M. González Galli $(\bowtie) \cdot$ E. N. Meinardi

Biology Teaching Group, Training and Research Center

for Sciences Teaching, School of Science,

University of Buenos Aires (UBA),

Buenos Aires, Argentina

e-mail: lmggalli@yahoo.com.ar

E. N. Meinardi

e-mail: emeinardi@fibertel.com.ar
}

exceed biology, with major consequences for fields as far apart as epistemology and ethics (Ruse 2007). This is why, from the scientific literacy perspective, it is of utmost importance that the key concepts of evolutionary biology are properly understood.

The present study explores the problems associated with teaching and learning the natural selection model (NSM). The difficulties faced by biology teachers when addressing this subject are widely known: due to these impediments, many people do not properly understand or do not accept the theory of evolution (Alters and Nelson 2002; NASIM 2008). In particular, this work focuses on the occurrence of a predisposition to teleological thinking in students that is incompatible with the scientific model being taught and that appears to be highly resistant to being changed.

The main hypothesis in this work is that teleological thinking can be characterized as a core obstacle to properly learning the NSM - the word obstacle here being used as defined in science didactics (Astolfi 1997). Although the incidence of students' teleological thinking in learning many concepts has already been pointed out, this work highlights that its educational implications have not yet been fully explored. Also, the characterization of teleological thinking as an obstacle could become a powerful tool for educational intervention aimed at enhancing the evolution of students' thinking.

\section{Teleological Concepts of Biology Students}

Comprehensive research in many different countries has shown that students' misconceptions are as diverse as they are abundant (Alters and Nelson 2002; Anderson et al. 2002; Bishop and Anderson 1990; Brumby 1979, 1980; Demastes et al. 1998; Gené 1991; Hallden 1988; Jungwirth 1975; Kattmann 2008; Lucas 1971; Martin 1983; Settlage 
1994; Smith 1994; Zohar and Ginossar 1998; Zuzovsky 1994, among others.). For instance, many biology students believe that:

acquired traits are inherited

the onset of the human species was predetermined evolution implies progress

living organisms can change according to their needs

Many of these ideas conform to a teleological view of the organic world (Bardapurkar 2008; Ziegler 2008).

An explanation is said to be teleological when it resorts to notions such as ends, goals, purposes, or objectives (Rosenberg and McShea 2008). For instance, if we ask ourselves, "Why did John switch the TV on?" And we respond, "To watch his favorite program," we are giving a teleological explanation. Our explanation resorts to one of John's goals: watching his favorite program. In this example, resorting to the notion of goal does not bring conflict since we assume that John is a conscious and intentional being, capable of conceiving goals and purposes. However, teleological explanations are habitually used to explain the behavior of systems to which we cannot easily attribute intention and consciousness. These kinds of explanations are common in biology (Mayr 1998; Rosenberg and McShea 2008). Hence, expressions like the following examples: "A flower produces perfume in order to attract pollinizers," "Lions usually live in groups called prides in order to be able to hunt for big prey," or "Whales have a thick layer of fat under their skin in order to protect themselves from the cold." The attribution of function also has teleological connotations. Examples of this are: "The function of the heart is to pump blood," "The function of photosynthesis is to produce glucose," or "The function of decomposition is to recycle nutrients in the ecosystem." Note that "The function of the heart is to pump blood" can easily be replaced by "Organisms have hearts in order to pump blood." Teleological examples are characterized by the use of function, purpose, and objective terminology as well as statements that declare that something exists for a reason (Mayr 1998).

Research done in the field of biology didactics indicates that students have resistant misconceptions of a teleological nature. These results coincide with numerous studies in the field of psychology highlighting the key role that teleological thinking has in the way people interpret the biological world (Lombrozo and Carey 2004; Keil 1998; Kelemen 1999a, b; Evans 2001; Inagaky and Hatano 2004; Opfer 2003; Atran 1998, 2001). For example, some authors point out that young children show a "promiscuous teleology" according to which the existence of all natural objects (like mountains, rivers and living beings) responds to certain purposes, frequently associated to human needs. This teleological view is then restricted, in teenagers and adults, to living beings only (Kelemen 1999a, b). Curiously, these studies have seldom been cited in the domain of education.

This general kind of teleological thinking relating to living organisms is eventually narrowed down to more specific ideas such as "Felines have developed sharp protractile claws in order to hunt down their prey." In the case of evolution, the wide range of students' teleological conceptions can be reduced to variations of the following general ideas:

1. The evolutionary process is directed toward the production of certain lineages or species (especially human beings).

2. The evolutionary process is directed toward ensuring the survival of a species.

As a consequence of the purpose assumed in (2), most students believe that:

3. Individual variations appear according to needs imposed by the environment: these are directed toward overcoming survival challenges (see, for example, Bardapurkar 2008).

In this way, biology students tend to assume that all biological features have some function and that evolutionary changes appear always as a result of particular goals. For instance, most students assume that organisms inevitably tend to lose those characteristics that they no longer need, or that mutations involving adaptation advantages for the species are more likely to occur. Therefore, adaptation from this point of view becomes the outcome of the transformation processes of each individual in response to its survival needs.

On the other hand, the functional nature of teleological conceptions has been underestimated in the literature related to learning and teaching the NSM (Kelemen 1999a). Even if it is assumed that organisms do not respond to certain purposes, it must be admitted that it appears as if they actually respond to some purposes. The behavior of biological systems seems to be directed to purposes because it is mainly the product of natural selection, which is responsible for the biological design. In fact, assuming that biological systems (either individual organisms or their parts) pursue some purpose is an excellent guide to predicting how these systems will behave (Dawkins 1996; Dennett 1987). This is why some authors suggest that this way of thinking is an adaptation (a product of natural selection). In this context, it is hardly surprising that when thinking about how organisms evolve, people assume that evolution is closely related to the pursuit of certain purposes, such as survival. It is this functionality - this explanatory and predictive power-which explains the resistance to changing these conceptions. Why should people change their way of thinking when this appears to 
be corroborated by everyday experience? This way of thinking predicts that living beings are adapted and adaptable systems, and so they are. Of course, the scientific model has a broader explanatory power, and is more consistent, than the teleological thinking shown by students. However, evidence showing the limitations of teleological conceptions does not occur spontaneously. Hence, it is not easy to make students feel the shortcomings of their thinking system, and it is even harder for them to replace it with a different set of counterintuitive explanations such as Darwinism.

It is possible to affirm that students interpret adaptation phenomena in a teleological way: individual organisms are born essentially with those traits they need; in certain conditions, these can be tailored to their needs. This is inconsistent with the Darwinian model. We will use the term "common sense teleology" to refer to this nonDarwinian way of thinking. This expression refers to the thinking described by cognitive psychology.

For this work, the influence of religious thinking on evolution has not been specifically undertaken, considering the more general non-religious teleological point of view. In fact, some authors argue that religious beliefs are built around prior teleological thinking (Dawkins 2006; Kelemen 2004a, b). Although acknowledging that a religious education complicates further the teaching of evolution, our purpose in this study is to analyze the relevance to the teaching process of a way of thinking that is common to both religious and non-religious people.

Finally, a remark about the use of the term "Lamarckian," sometimes used to describe the spontaneous way of pupils' thinking described here as teleological. The work we present indicates that the theoretical frame of students is not Lamarckian inheritance-i.e., the inheritance of acquired characteristics from one generation to the next - but rather the functional finalist thinking described by cognitive psychological studies, which we refer to here as "common sense teleology." The differences between the students' way of thinking and Lamarck's theory are significant (see, for instance, Kampourakis and Zogza 2007).

\section{“Common Sense Teleology" as an Obstacle}

The concept of obstacle, as used in science didactics, is inspired by the concept of "epistemological obstacle" suggested by the French philosopher Gaston Bachelard (1938). This notion has been fully developed by, among others, pedagogues like Jean Pierre Astolfi and Michael Develay (Astolfi and Develay 1989). Within this theoretical framework, an obstacle is a way of thinking which is lateral or crosswise, as well as functional (Astolfi 1994). This characterization highlights the difference between an obstacle and a mere conception. The lateral or crosswise nature of an obstacle indicates it is a general way of thinking that can be expressed in relation to many specific issues rather than just notions that are closely linked to a conceptual domain. For example, linear causal thinking presupposes that each event has a unique and immediate cause. This way of thinking could become an obstacle when formulating concepts related, for instance, to trophic relationships in an ecosystem or to evolutionary processes. The functional explanatory nature of an obstacle indicates that this general way of thinking allows people to find explanations for understanding phenomena of interest to them. When such a thought system competes with a scientific model that we intend to teach (i.e., it can provide an explanation for a particular phenomenon), then it becomes an obstacle.

It should be emphasized that from this perspective, an obstacle should not be considered a purely negative factor. While it is true that this thinking system may be incompatible with the scientific model, therefore hindering the learning process, it is equally true that this way of thinking is initially the only explanatory framework available to students for the analysis of a new concept. That is why these ideas must be taken into account when teaching, facilitating both efforts to make them explicit and to have them questioned by students.

Why can "common sense teleology" be characterized as an obstacle? Evidence in two significant fields allows us to consider this: both cognitive psychology and science didactics converge in highlighting the omnipresence and functional importance of this way of thinking. Psychology shows that teleological thinking in relation to living beings is a typical cognitive feature of youngsters and adults - this way of thinking being both crosswise (applies to all biological domains) and functional (allows finding explanations to biological phenomena). On the other hand, biology didactics highlights the omnipresence and the resistance of pupils' teleological conceptions as recurrent problems for teaching the NSM (Anderson et al. 2002; Bishop and Anderson 1990; Bartov 1978, 1982; Settlage 1994; Zuzovsky 1994; Zohar and Ginossar 1998, among others). Teleological thinking in relation to many subjects is deeply ingrained and has been found even among chemistry students and teachers (Talanquer 2007).

\section{Implications for Teaching}

Teleology has always been regarded as a problem for teaching based on the assumption that scientific models are not teleological. Hence, these are two incompatible principles at odds with one another. Teachers' worries regarding this subject often translate into forbidding students the use 
of teleological expressions; at best, the heuristic value of teleological thinking has been recognized (Kattmann 2008; Zohar and Ginossar 1998). However, if cognitive psychology results are taken seriously, it can be concluded that it is impossible to eliminate teleological thinking from students. Considering its functional nature, we should ask if its elimination is desirable at all.

The theoretical framework adopted in this study suggested that we should make students aware of the way they tend to think when analyzing biological systems. In order for this to happen, we need to make explicit ways of thinking that are normally implicit. This is a necessary condition for the development of students' capacity to identify their own ways of reasoning. In turn, this would allow them to evaluate their own style of thinking and adopt it to a particular scientific model of reference. This proposal implies giving a central role to students' cognitive abilities. Therefore, finding the key differences between their a priori conceptions and the scientific model becomes important. Far from banning teleological expressions in the classroom, this perspective acknowledges the need to resort to these (Zohar and Ginossar 1998). Educators should bring to light the teleological obstacle so as to turn it into the object of analysis. The challenge for teachers would then be that their students acknowledge which of their a priori suppositions are incompatible with the scientific model and which are advantageous. This understanding would serve as a stepping stone toward students monitoring themselves for their own teleological thoughts and correcting them within the NSM framework.

What is important then is not correcting ways of expressing thoughts but making ways of thinking visible. According to this proposal, it is not wrong to ask, "What is the X trait good for?" Nor is it wrong to create hypotheses such as "the X trait is good for F." It is not even wrong to say that certain organisms have developed throughout their evolution an " $\mathrm{X}$ " trait to perform a function " $F$ ". These expressions could be both the manifestation of "common sense teleology" and genuine Darwinian reasoning. As a matter of fact, biologists frequently use these sorts of expressions. Given this ambiguity, the important thing is that students are able to explain what exactly they mean by using these expressions. Within the classroom context, it is not easy to identify students' reference framework from these expressions. How could teachers facilitate making these implicit theoretical frameworks explicit? From this perspective, teachers will only be able to know the reference framework of their students by making them acknowledge it when faced with questions that require complex explanations.

Identifying obstacles can also be a powerful guide to the design of classes. This is the central idea of the notion of "objective-obstacle" due to Jean Louis Martinand (Astolfi
1997; Martinand 1986). Basically, the idea is that overcoming the obstacle becomes the main objective of classes in the long run. This approach implies designing activities that allow to make explicit, and to question, obstacles or their expression. As well, it implies highlighting the aspects of the model to be taught that are incompatible with the obstacle. In the case of the NSM, for instance, the dicey nature of the origin of genetic variability constitutes a central point. Analysis of evidence favoring the scientific model and refuting misconceptions can be very useful. However, such a procedure cannot totally overcome the obstacle (Astolfi 1994). The logic of refutation, implicit in some models of conceptual change, has serious limitations given the ingrained character of the structures of thought we call obstacles.

Some ways of working within the theoretical framework of this study are suggested in the following section:

- In general, students' teleological expression should not be censored. If the spontaneous form of expression is teleological, then it will be necessary to seek further for the patterns of thought underlying such forms of expression. Students' ideas should come out in the classroom in order to make them the object of analysis. The objective is to catalyze the evolution of the underlying thought structures and not merely superficially change the ways of expression.

- It is necessary to engage students in activities that involve explaining and debating. If a task does not require activating these cognitive abilities, then the thought structures of students remain inert and "invisible" to both teacher and students. Examples of these would be: asking students to explain how and why bacteria become resistant to an antibiotic or how and why did fish living in caves lose the sense of sight. In order for students' thought structures to become explicit, an atmosphere of confidence is required so that they do not feel undercut when expressing their ideas.

- In higher courses, we can explain to students what teleological explanations consist of. Then students can be given a list of statements (some of which are teleological) and be asked to identify which these are. In those cases where teleological expressions are not acceptable, students could be asked to express the same idea in a non-teleological manner. For example, to elaborate a non-teleological text replacing the statement "Nature has provided llamas with a thick coat of hair so that they can endure the bitter cold climate of the Andes."

- Students can be asked to write down their initial explanations (prior to teaching the NSM) about a particular problem, for instance, the development of resistance to insecticides. Once the model has been 
learned, they can read their initial explanations in order to identify teleological expressions in them. This exercise will facilitate becoming conscious of what students thought then and what they think now so that they can see the evolution of their way of thinking. Significantly, many will acknowledge that they still tend to think in a teleological manner concerning certain problems.

- Many times, students' teleological reasoning is guided by analogy. For example, students might think that living organisms resolve their survival needs in a manner similar to that of human beings. This analogy should then be explicitly brought up so students have the chance to consider how these processes are similar or different. An example might be the remarkable convergence between certain technologies and certain organic adaptations: for instance, animal echolocation, used by several animals like bats, and human echolocation or SONAR (sound navigation and ranging), commonly used by submarines. The students can be asked to write a text explaining the origin of both systems and pointing out differences and analogies between both of them that they consider important. Some might fear that this activity could encourage teleological thinking in students. However, it should be pointed out that students make these analogies in any case, and therefore, it is better to make these analogies explicit, rather than leaving them concealed, so that they can become the object of analysis.

- Students can be asked to analyze the concept of mutation-and mutants, such as those appearing in science fiction: Spiderman, the Incredible Hulk, etc.in order to identify how these ideas contradict scientific models (González Galli et al. 2008). The concept of mutation, implicit in much science fiction, has a lot in common with students' teleological misconceptions such as, "mutations are directed toward adaptation." Other science fiction productions can be used to analyze other teleological misconceptions. For example, the recent film "Avatar" (Avatar, 2010, directed by James Cameron) presents a vision of a planet that functions like a "super-organism." According to this idea, which relates to James Lovelock's hypothesis of Gaia, each organism in this planet has a function in the overall sustainment of the planet as a whole. This is a conception with strong teleological connotations and incompatible with the NSM (Dawkins 1998; Kirchner 2002). Many people appear to have conceptions of this kind (Kelemen and Rosset 2009). When revising ideas in science fiction productions, students - in an indirect manner-revise their own conceptions.

- Students can be asked to analyze the theoretical framework underlying a particular expression. For example, they could analyze the statement "Polar bears turned white during their evolution in order to camouflage in the snow." They could then be asked to think what this statement would mean if made by a Darwinist biologist, or a Lamarckian biologist, or by a relative or friend knowing little biology. This type of analysis is useful so that students become conscious of the ambiguous nature of linguistic expressions and the need to explain more clearly what they want to say.

- Once the obstacle appears to have been overcome, it is useful to propose to students other different and more complex cases than those analyzed. It is common that the obstacle may reappear. Even students who can provide correct Darwinian explanations in cases similar to those already discussed in the classroom might resort to teleological explanations when they cannot apply the model to more complex cases. For example, this "reversion" is common when analyzing for the first time cases of loss of structure, such as the example mentioned of blind fish in caves. This type of exercise is useful so that students become aware that teleological thinking may still be present. In this way, they can understand the need to be alert and vigilant for the tendency of this way of thinking.

These strategies are aimed at developing students' metacognitive skills. Therefore, the educational benefit of this approach in the classroom exceeds the specific topic being taught since the development of these cognitive tools can improve students' learning in other areas.

\section{About the Nature of the Natural Selection Evolution Model}

This final section highlights another potential source of difficulties for the learning and teaching of the NSM.

Teleology constitutes a central problem for the philosophy of biology (Allen et al. 1998), in particular the legitimacy of teleological explanations (e.g., Hull and Ruse 2007; Mayr 1998; Ruse 1973; Sober 2000). It is within this framework that explanations based on the Darwinian model are the object of debate. The reason is that teleological explanations seem to invert the temporal relation between causes and effects (since goals are in the future) and suggest some sort of intentionality in the universe. However, several authors have suggested that certain teleological explanations are legitimate from a scientific viewpoint. More specifically, some authors maintain that the NSM, and explanations derived from it, have a teleological nature (Ayala 1970, 1995, 1998, 1999; Dennett 1995, 1987; Lewens 2002; Ruse 2000, 2007; Lennox 1993, 1994, 2008, 2010; Caponi 2003; Short 2001). This 
suggestion does not presuppose in any way that evolution through natural selection implies a directionality ensuring the production of certain species, nor that individual variation is oriented toward an adaptation gain for the species. Those considering that the NSM is teleological consider as well that this is perfectly legitimate from the scientific viewpoint. Darwinian explanations are completely naturalistic and do not imply any metaphysical assumptions that are incompatible with scientific standard criteria, which means that for these authors, the NSM implies a perfectly natural form of teleology that has nothing to do with preDarwinian teleology. Thus, while some authors consider that Darwin eliminated teleology from biology, others consider that he naturalized it (Lennox 2008, p. 81; Sober 2000, p. 84).

The different arguments given by these authors-not detailed here-converge in pointing out the teleological nature of the NSM. For instance, it could be mentioned that for Michael Ruse, teleological language in biology relies on a metaphor (the metaphor of design; Ruse 2000, 2008). This would seem to suggest that the NSM is not teleological in itself. However, Ruse claims that reliance on metaphor is inevitable in order to explain adaptation. If metaphor is part of the theory, then the theory would be teleological. Ruse points out that non-teleological explanations exclusively based on past facts to explain adaptation can only be retrospectively constructed after having thought about the metaphor of design. First we ask: "what for?" of a particular trait analyzed, and then we construct the Darwinian explanation. Thus, argues Ruse, we use the metaphor of design and then pretend not to have used it. As Ruse points out, as long as it is not possible to explain adaptation phenomena without resorting to the metaphor of design (evidently teleological), then both the phenomenon to be explained and the explanations themselves are, in a relevant sense, teleological.

Although the suggestion that the NSM is teleological is polemic, it might be relevant to consider it. From a more general perspective, it is necessary to analyze the specific characteristics of a scientific model to be taught so as to identify intrinsic knots that may complicate both teaching and learning. In our particular case, it could be thought that the teleological nature of the NSM would increase the difficulty in dealing with students' misconceptions exposed earlier. If the model in itself is teleological, then it could be even more difficult to eliminate teleological expressions in biology. On the other hand, if the model is teleological, then the capability of applying the Darwinian model to explain the organic world requires the activation of teleological thinking. Finally, the similarity between student's non-Darwinian teleological expressions and teachers' Darwinian teleological expressions could complicate identifying and distinguishing both theoretical frameworks.
These considerations reinforce our previous conclusions that what is important for teaching is not eliminating teleological thinking but rather stimulating students' capacity to be conscious of the existence of such ways of thinking (meta-cognition).

Even in the case that the NSM is not considered teleological, the problem remains that biologists and teachers resort frequently to teleological expressions. These expressions are powerful means of expressing NSM ideas. As mentioned earlier, the trouble is that students produce the same type of expressions from a completely different theoretical framework. Whereas students' non-Darwinian teleological expressions are "common sense teleology," as described by cognitive psychologists, biologists, and teachers, teleological expressions are, on the contrary, expressions of the Darwinian NSM. Therefore, it is still necessary to explicitly identify and distinguish both these theoretical frameworks in order to stimulate the consciousness of such different ways of thinking.

\section{Conclusion}

Teleological thinking in relation to living beings is a fundamental characteristic of our psyche, as highlighted both by biology didactics and cognitive psychology. The notion of obstacle is a powerful framework for analyzing the implications to education of certain thinking processes and for the design of useful didactics oriented to overcoming them.

This study highlights the need to revise some educational objectives, in particular the pretension of eliminating teleological expressions and the ways of thinking behind them. This conclusion is not only supported by the acknowledgement of the heuristic value of it: teleological thinking is a characteristic of our cognitive apparatus that is neither possible - nor desirable - to eliminate. From this perspective, educational work should focus more on developing students' meta-cognitive capacities. Students should be capable of recognizing the teleological tendencies of their thinking and understand the limitations and dangers of this. Talanquer (2009) reaches similar conclusions about what he calls cognitive constraints. This work highlights the necessity of reflecting upon the question of teleological explanations in biology and the nature of the NSM.

The approach developed in this work does not pretend to deal with all difficulties encountered when teaching evolution, such as probabilistic logic, religious faiths, or emotional resistance. The perspective presented here draws attention to the necessity of analyzing students' conceptualizations as well as the intrinsic complexities of the scientific models teachers would like students to learn. 
Acknowledgments This paper has been funded by the National Scientific and Technical Research Council (CONICET) of the Ministry of Science, Technology and Productive Innovation, under the Presidency of the Nation, and by the UBACyT X 141 Project from the University of Buenos Aires.

\section{References}

Allen C, Bekoff M, Lauder G. Nature's purposes. Analyses of function and design in biology. Cambridge: MIT Press; 1998.

Alters B, Nelson C. Perspective: teaching evolution in higher education. Evolution. 2002;56:1891-901.

Anderson D, Fisher K, Norman G. Developement and Evaluation of the conceptual inventory of natural selection. J Res Sci Teach. 2002;25(10):952-78.

Astolfi J. El trabajo didáctico de los obstáculos, en el corazón de los aprendizajes científicos. Enseñanza de las Ciencias. Revista de investigación y experiencias didácticas. 1994;12:206-16.

Astolfi J. Mots-Clés de la didactique des sciences, chapter 12. París: De Boeck \& Larcier sa; 1997.

Astolfi J, Develay M. La didactique des sciences, chapter 2. Paris: Presses Universitaires de France; 1989. p. 2.

Atran S. Folk biology and the anthropology of science: cognitive universals and cultural particulars. Behav Brain Sci. 1998;21:547-69.

Atran S. Folk biology. In: Wilson RA, Keil FC, editors. The MIT encyclopedia of the cognitive sciences. Cambridge: MIT Press; 2001. p. 216-217.

Ayala F. Teleological explanations in evolutionary biology. Philos Sci. 1970;37:1-15.

Ayala F. The distinctness of biology. In: Weinert F, editor. Laws of nature: essays on the philosophical, scientific and historical dimensions. New York: Walter de Gruyter; 1995.

Ayala F. Teleological explanations versus teleology. Hist Philos Life Sci. 1998;20:41-50.

Ayala F. Adaptation and novelty: teleological explanations in evolutionary biology. Stud Hist Philos Biol Biomed Sci. 1999;21:3-33.

Bachelard G. La formation de l'esprit scientifique. Paris: Vrin; 1938.

Bardapurkar A. Do students see the "Selection" in organic evolution? A critical review of the causal structure of student explanations. Evol Educ Outreach. 2008;1:299-305.

Bartov H. Can student be taught to distinguish between teleological and causal explanations? J Res Sci Teach. 1978;15:567-72.

Bartov H. Teaching students to understand the advantages and disadvantages of teleological and anthropomorphic statements in biology. J Res Sci Teach. 1982;18:79-86.

Bishop B, Anderson C. Students conceptions of natural selection and its role in evolution. J Res Sci Teach. 1990;27(5):415-27.

Brumby, M. Student's preceptions and learning styles associated with the concept of evolution by natural selection. Unpublished doctoral dissertation, University of Surrey, UK; 1979.

Brumby M. Misconceptions about the concept of natural selection by medical biology students. Sci Educ. 1980;68(4):493-503.

Caponi G. Darwin: entre Paley y Demócrito. História, Ciências, Saúde. Manguinhos. 2003;10:993-1023.

Dawkins R. Climbing mount improbable. Viking: Viking; 1996.

Dawkins R. Unweaving the rainbow. Science, delusion and the appetite for wonder, chapter 9. London: Penguin; 1998.

Dawkins R. The God delusion. New York: Houghton Mifflin; 2006.

Demastes S, Good R, Peebles P. Patterns of conceptual change in evolution. J Res Sci Teach. 1998;33(4):407-31.
Dennett D. The intentional stance, chapters 7 and 8. Cambridge: Bradford Books; 1987.

Dennett D. Darwin's dangerous idea: evolution and the meanings of life, chapter 8. New York: Simon and Schuster; 1995.

Evans E. Cognitive and contextual factors in the emergence of diverse belief systems: creation vs evolution. Cogn Psychol. 2001;42:21766.

Gené A. Cambio conceptual y metodológico en la enseñanza y el aprendizaje de la evolución de los seres vivos. Un ejemplo concreto. Enseñanza Cienc. 1991;9(1):22-7.

González Galli L, Revel Chion A, Meinardi E. Actividades centradas en obstáculos para enseñar el modelo de evolución por selección natural. Rev Educ Biol. 2008;11:52-5.

Hallden $O$. The evolution of species: pupil perspectivas and school perspectives. Int J Sci Educ. 1988;10:541-52.

Hull D, Ruse M, editors. The Cambridge companion to the philosophy of biology. Cambridge: Cambridge University Press; 2007.

Inagaky K, Hatano G. Vitalistic causality in young children's naive biology. Trends Cogn Sci. 2004;8:356-80.

Jungwirth E. The problem of teleology in biology as a problem of biology-teacher education. J Biol Educ. 1975;9(6):243-6.

Kampourakis K, Zogza V. Student's preconceptions about evolution: how accurate is the characterization as "Lamarckian" when considering the history of evolutionary thought? Sci Educ. 2007; 17:393-422.

Kattmann U. Learning biology by means of anthropomorphic conception? In: Hammann M, Reiss M, Boulter C, Dale Tunnicliffe S, editors. Biology in context. Learning and teaching for the twenty-first century. London: Institute of Education, University of London; 2008. Keil F. The birth and nurturance of concepts by domain: the origins. p. 7-17.

Keil F. The birth and nurturance of concepts by domain: the origins of concepts of living things. In: Hirschfeld L, Gelman S, editors. Mapping the mind. Domain specificity in cognition and culture. Cambridge: Cambridge University Press; 1998. p. 234-254.

Kelemen D. Functions, goals and intentions: children's teleological reasoning about objects. Trends Cogn Sci. 1999a;3:461-8.

Kelemen D. The scope of teleological thinking in preschool children. Cognition. 1999b;70:241-72.

Kelemen D. Are children "intuitive theists"? Psychol Sci. 2004a;15:295301.

Kelemen D. Counterintuition, existential anxiety, and religion as a byproduct of the designing mind. Behav Brain Sci. 2004b;27:73940.

Kelemen D, Rosset E. The human function compunction: teleological explanation in adults. Cognition. 2009;111:138-43.

Kirchner L. The Gaia hypothesis: fact, theory and wishful thinking. Clim Change. 2002;52:391-408.

Lennox J. Darwin was a teleologist. Biol Philos. 1993;8:409-21.

Lennox J. Teleology by another name: a replay to Ghiselin. Biol Philos. 1994;9:493-5.

Lennox J. Darwinism and Neodarwinism. In: Sarkar S, Plutynski A, editors. A companion to the philosophy of biology, chapter 5 . Blackwell: Malden; 2008. p. 77-98.

Lennox J. Darwinism. In: Zalta E, editor. The Stanford encyclopedia of philosophy. Spring: Stanford; 2010. http://plato.stanford.edu/ archives/spr2010/entries/darwinism/.

Lewens T. Adaptationism and engineering. Biol Philos. 2002;17:1-31.

Lombrozo T, Carey S. Functional explanation and the function of explanation. Cognition. 2004;99:167-204.

Lucas A. The teaching of "adaptation”. J Biol Educ. 1971;5:86-90.

Martin, M. An examination of students misconceptions in genetics. In: Helm H, Novak JP, editors. International Seminar on Misconceptions in Science and Mathematics. Cornell; 1983. pp. 218-225.

Martinand J. Connaître et transformer la matière. Berna: Peter Lang; 1986. 
Mayr E. This is biology. The science of the living world, chapter 4 . Cambridge: Harvard University Press; 1997.

Mayr E. Toward a new philosophy of biology. Observations of an evolutionist, chapter 1. Cambridge: Harvard University Press; 1998.

National Academy of Sciences and Institute of Medicine. Science, Evolution, and Creationism. Washington, D.C.: The National Academies Press; 2008.

Opfer JE. Life, liveliness, and living kinds: how young children think about the biological world [Review of Young children's naive thinking about the biological world]. Int J Behav Dev. 2003;27:375-80.

Rosenberg A, McShea D. Philosophy of biology. A contemporary introduction. New York: Routledge; 2008.

Ruse M. Philosophy of biology. London: Hutchinson; 1973.

Ruse M. Teleology: yesterday, today, and tomorrow? Stud Hist Philos Biol Biomed Sci. 2000;31:213-32.

Ruse M. Charles Darwin (Blackwell great minds). Malden: Blackwell; 2008.

Ruse M. Charles Darwin, chapter 3. Oxford: Blackwell; 2007.
Settlage J. Conceptions of natural selection: a snapshot of the sensemaking process. J Res Sci Teach. 1994;31(5):449-57.

Short T. Darwin's concept of final cause: neither new nor trivial. Biol Philos. 2001;17:323-40.

Smith M. Counterpoint: belief, undestanding, and the teaching of evolution. J Res Sci Teach. 1994;31(5):591-7.

Sober E. Philosophy of biology, chapter 3. Oxford: Westview; 2000.

Talanquer V. Explanations and teleology in chemistry education. Int J Sci Educ. 2007;29:853-70.

Talanquer V. On cognitive constrains and learning progressions: the case of "structure of matter". Int J Sci Educ. 2009;31:2123-36.

Ziegler D. The question of purpose. Evol Educ Outreach. 2008;1:44-5.

Zohar A, Ginossar S. Lifting the taboo regarding teleology and anthropomorphism in biology education-heretical suggestions. Sci Educ. 1998;82:679-97.

Zuzovsky R. Conceptualizing a teaching experience on the development of the idea of evolution: an epistemological approach to the education os science teachers. J Res Sci Teach. 1994;31 (5):557-74. 